\title{
A Comparative Study on the Utilization Configuration and Characters of Urban Comprehensive Park in China and Korea
}

\author{
Xiaoyan $\mathrm{Li}^{1,2}$, a, Seicheon Kim², b, Kwangwoo Hong ${ }^{2, \mathrm{c}}$, Xinmei Jin ${ }^{2, \mathrm{~d}}$, Yingyi Du \\ ${ }^{1}$ Ecology and Landscape Architecture College, Dezhou University, Dezhou 253000, China \\ ${ }^{2}$ Landscape Architecture Department, Chonbuk National University, Jeonju 561765, Korea \\ alixiaoyan-qq@163.com, bsckim@jbnu.ac.kr, ckwhong81@jbnu.ac.kr, djxm1221@naver.com
}

\begin{abstract}
Based on the survey of Daming-lake park in Jinan city of China and Deokjin park in Jeonju city of South Korea, by on-the-spot investigation, questionnaire survey and in-depth interview, the study analyzed the users' essential attributes, visiting characteristics, landscape reference, and compared the differences of utilization characteristics between two parks in order to offer a basis suggestion for humanization designing of urban parks.
\end{abstract}

Keywords: urban park; utilization configuration; use characteristics.

\section{Introduction}

As an important part of city landscape system, urban comprehensive park, which can not only supply large area of green space but also offers variety of out-door recreation, sports and leisure facilities, plays an irreplaceable advantage and role in cityscape and environment protection[1].

Many scholars have studied landscapes from different domains and different lays, and achieved many fruits. Arriaza (2004), for instance, according to serious investigation and summed assessing the visual quality of landscapes [2]. Van den Berg and Koole (2006) found that the variables of place of residents, age, socio-economic status, farming background, preference for greening political parties and recreational motives were correlated with relative preferences for wild versus managed nature scenes [3]. Huazhang et al. (2013) explored landscape perception and recreation needs in urban green space in Fuyang, and found the main recreation inclination and landscape preference so that they can give some corresponding improvement measure proposals [4].

This study attempts to compare the differences of demographic and social economic attributes, the utilization characteristic between Deokjin Park in Jeonju and Daming-lake Park in Jinan. Furthermore, preference rating for landscape elements and attributes of urban parks aims to reveal the details of the content and design of landscape structure appealing to the respondents, which we expect to generate more visit.

\section{Research method}

In this study, we take Deokjin park in Jeonju, Korea, and Daming-lake park in Jinan, China as samples. The data for this study were mainly derived from on-the-spot investigation, questionnaire survey and in-depth interview, which were distributed randomly to the visitors in above mentioned parks from February $10^{\text {th }}$ to April $20^{\text {th }}$ in 2015. Taking the form of 'spot-distributing and spot-collecting', the questionnaire survey was carried out in half weekdays and half weekends to make sure of the randomicity and typicality of distribution. Totally 700 questionnaires were distributed and 662 effective questionnaire paper were collected. The effective percentage is $94.6 \%$. Descriptive statistics was conducted to analyzed visitors' attributes, the characteristics of utilization, and the preference landscape elements. 


\section{Result and analysis}

The demographic and socio-economic characteristics. Visitors' activities relate to personality's gender, age, occupation, education, and other factors, in this study we set several items to record visitors' demographic and socio-economic attributes, as the results in Table 1.

Table 1 General facts samples by region

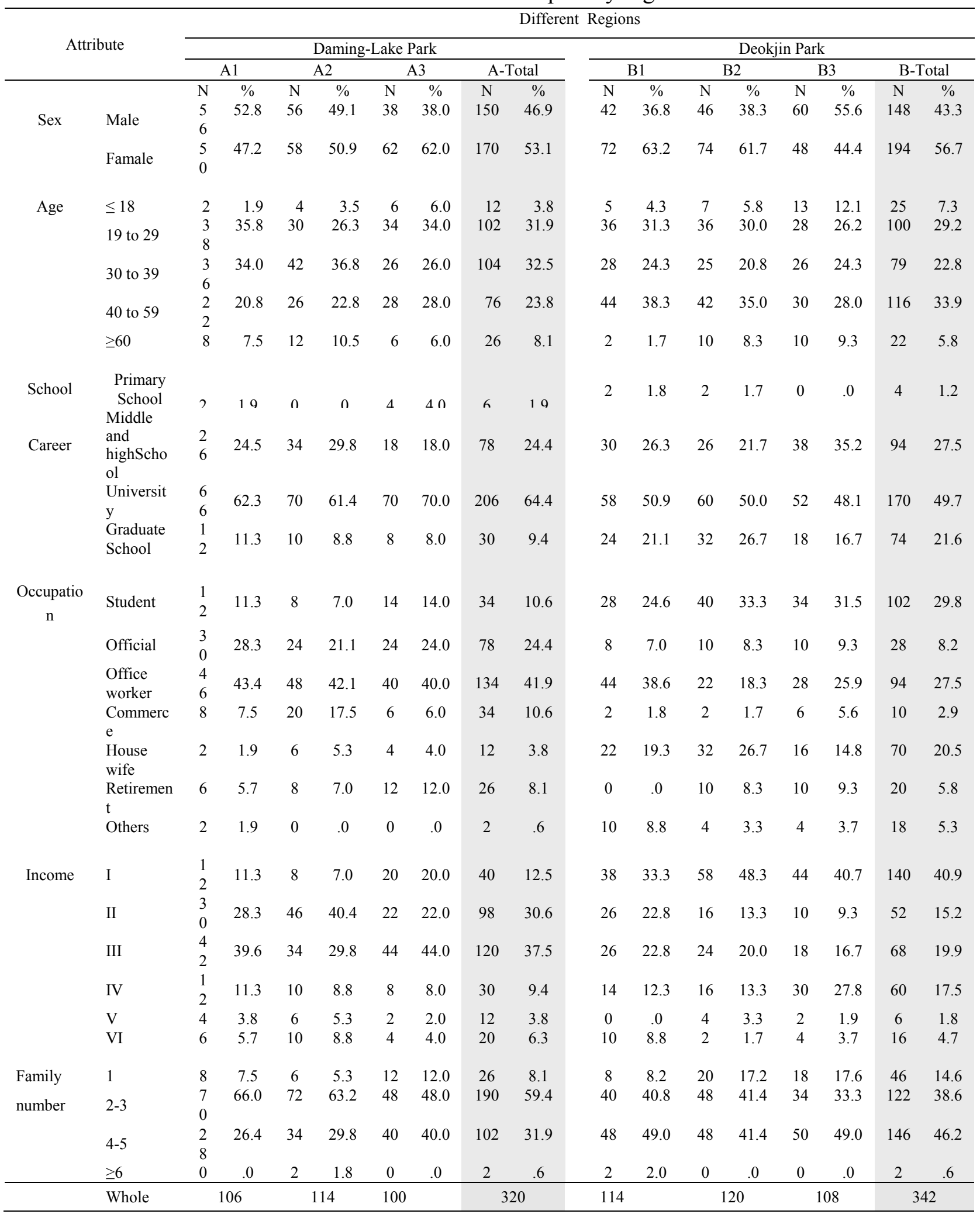


In order to keep a possible randomness, data were collected in three areas of each park; Because of different of currency and economic levels, the monthly income was transformed into 6 grades( I,II,III,IV,V,VI) as the consumption and economic levels in natives. The income values which are relate to each grade can be got in Table 2 .

Table 2 The classification of income grade in two countries

\begin{tabular}{|c|c|c|c|c|c|c|}
\hline & I & II & III & IV & V & VI \\
\hline KRW & $\begin{array}{c}\text { Less than } \\
100\end{array}$ & $101-200$ & $201-300$ & $301-400$ & $401-500$ & $\begin{array}{c}\text { More than } \\
500\end{array}$ \\
\hline RMB(yuan) & $\begin{array}{l}\text { Less than } \\
2000\end{array}$ & $\begin{array}{c}2001-400 \\
0\end{array}$ & $4001-6000$ & $6001-8000$ & $\begin{array}{c}8001-100 \\
00\end{array}$ & $\begin{array}{c}\text { More than } \\
10000\end{array}$ \\
\hline
\end{tabular}

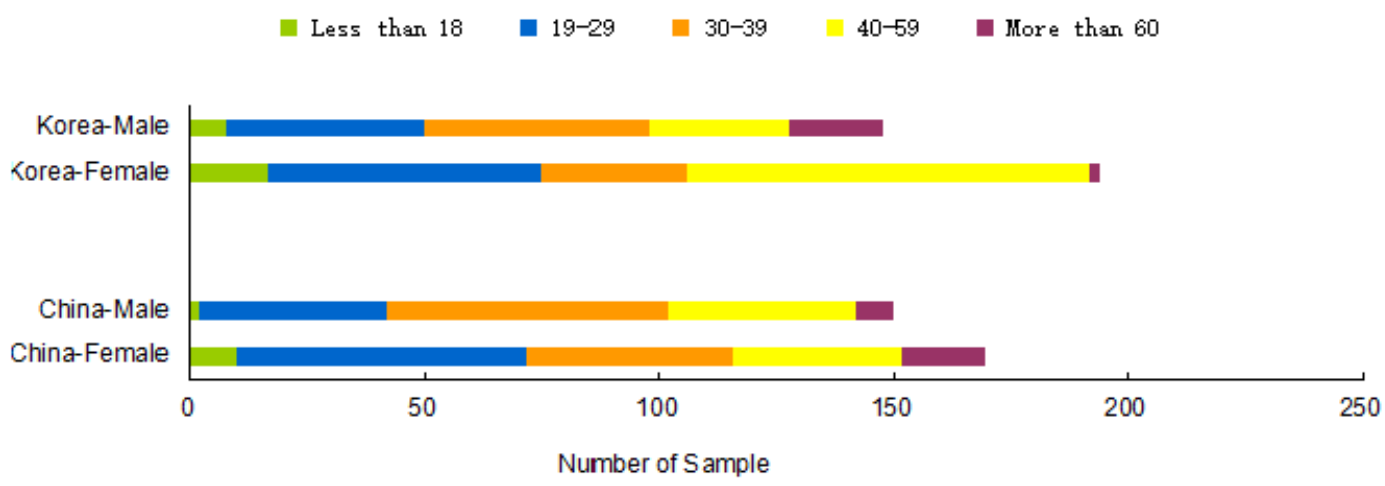

Fig. 1 Response to age structure based on male and female in two parks.

As we see in Fig. 1, among all visitors to Daming lake park, there are 46.9\% males and 53.1\% females while in Deokjin park the proportion of male and female is $43.3 \%$ and $56.7 \%$. More higher proportion of female may have a certain relationship with traditional family mode in Korea that 'Men's work centers around outside and women's work centers around home', so that women often have more time and opportunities to visit urban parks. In Damin-lake park, no matter male or female visitors, the proportion of below 18 and above 60 is a little low, with a probable reason that Chinese pupils have a heavy course load and little recreation time; In Deokjin park the stage between 40 and 59 holds a biggest proportion, because many Korea female center around home after they get married especially after having children, so no mater weekend or weekdays they have more relative free time to arrange.



Fig. 2 Response to occupation structure in two parks.

The official and company office workers in China institute an 'eight-hour working day system' and often can knock off at 5:30 pm., so some of them select to relax in park after work; However in Deokjin park investigation a high housewife proportion(20.5\%) and student proportion(29.8\%) were found, with a strong contrast (3.8\% and 10.6\%) in Daming-lake park. High student proportion dues to that Deokjin park locates near an university, and many college students and graduate students consist one important component of visitors.

Income grades obey a nearly normal distribution. In Deokjin park low-income takes a big proportion because of more students and housewife who don't take an economic occupation. For the 
living number of family, 2-3 persons or 4-5 persons pattern are mostly found, perhaps due to a phenomenon that two-generations or three-generations family mode.

Utilization characteristics of time. Integrating the response to seasons, workdays and detail times, it was found that overall, Chinese and Koran residents are inclined to visitor urban landscape in spring, weekends and vocation, but there's difference on the detail time, for instance Chinese residents prefer to visit in morning while Korean visitors like in afternoon and evening (Table 3). Maybe it relates to different life habits of two countries.

Table 3 Response to the utilization characteristics of visitors



Characteristics of transportation means, required time, and distance from home. Comparing the diversity of transportation means to Daming lake park, the vehicles to Deokjin park are mainly concentrated on only three types: on-foot(37.4\%), by bus(26.9\%) and self-driving(32.7\%) (Table 4), but Deokjin park have a better accessibility from the view of required-time and distance from home. About $87.7 \%$ Korean visitors could reach Deokjin landscape within 30 minutes while Chinese only 46.9\%. Accessibility is considered as an important index for a good urban park standard.

Table 4 Response to transportation means, required time, and distance from home

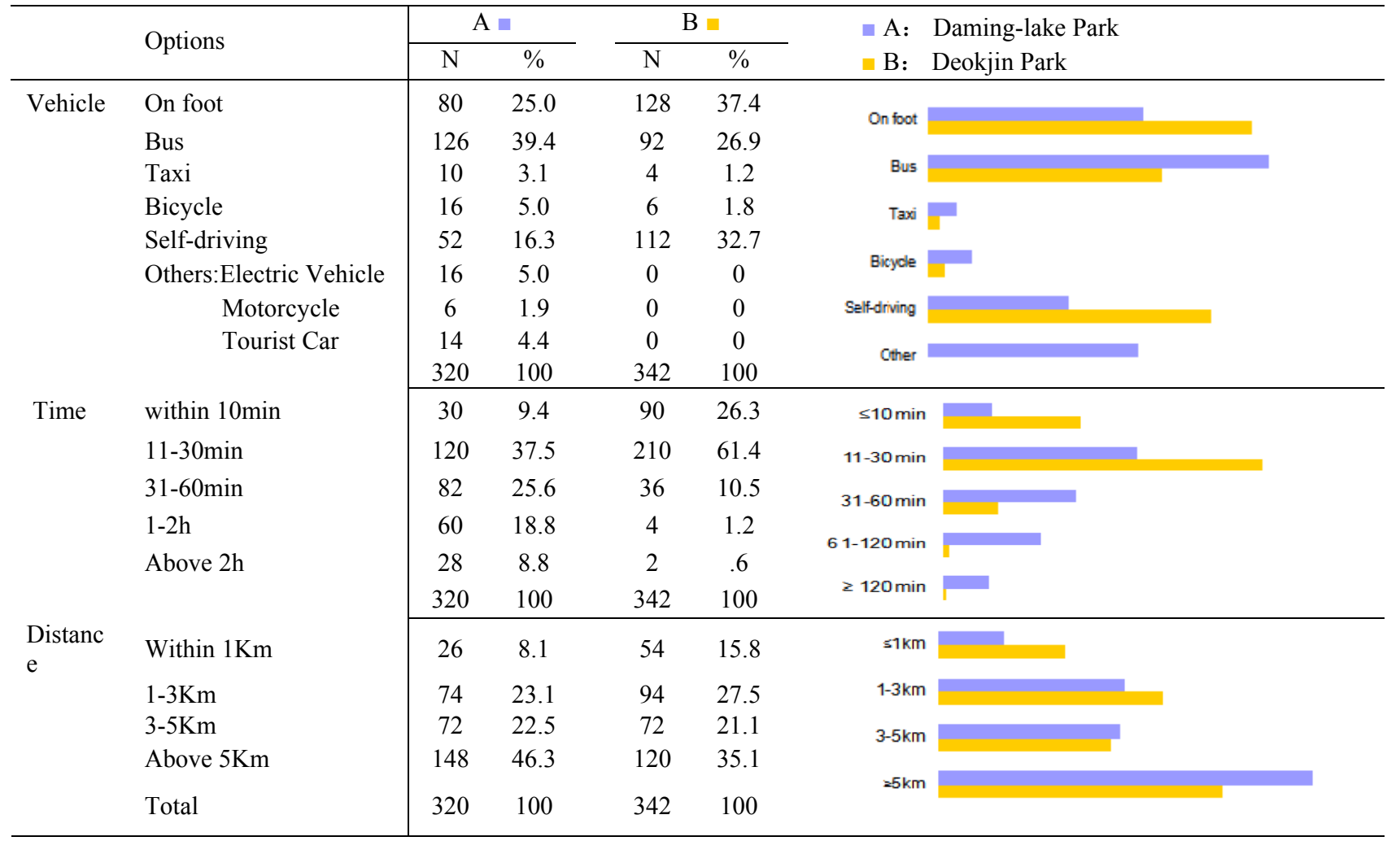


Visit frequency and visit purpose. The response to visit frequency shows a partial normal distribution, main visiting frequency to Daming lake park is 1-2times each month, purposes of visit are concentrated on 'walk, landscape viewing, taking photos', a certain proportion of 'accompanying elderly and children, morning exercise'; Among Deokjin park visitors, largest proportion visit frequency is 1-2 times each month, with the purpose of walk and landscape viewing.

\section{Proposal for planning of comprehensive park}

According analysis of the utilization and configuration of two parks, some different characters were found and may due to different social sex structure, life habit and work style patterns. In the planning of comprehensive parks, appropriate spaces and facilities which could satisfy different users should be well planned and developed, for instance, because of high female or student rate more facilities which suit for them should be given more considerations.

\section{References}

[1] Jihong FU. 2014. Constructing City with Regional Culture, Cultivating New Trend with Urban Landscape. Study on the Cultural Construction of Chongqing's Urban Landscape. Studies in Literature and Language, Vol.9 (3):177-181

[2] Arriaza,M., Canas-Ortega,J.F., Ruiz-Aviles,P., 2004. Assessing the visual quality of rural landscapes. Landscape and Urban Planning 69,115-125.

[3] Van den Berg, A.E., Koole,S.L., 2006. New wilderness in The Netherlands: an investigation of visual preferences for natural development landscapes. Landscape and Urban Planning 78, 362-372.

[4] Hua Zhang,Bo Chen and et. 2013. Landscape perception and recreation needs in urban green space in Fuyang, Hangzhou, China. Urban Forestry \& Urban Greening 12, 44-52. 